\title{
Thermal Oxidation of Copper for Favorable Formation of Cupric Oxide (CuO) Semiconductor
}

\author{
Uma Nerle and M. K. Rabinal* \\ (Department of Physics, Karnatak University Dharwad - 580 003, Karnataka, India) \\ *Corresponding author email: mkrabinal@yahoo.com
}

\begin{abstract}
Thermal oxidation of copper has been restudied to control the formation of photovoltaic active cupric oxide $(\mathrm{CuO})$ phase against the cuprous oxide $\left(\mathrm{Cu}_{2} \mathrm{O}\right)$ phase. It has been established that the thermal oxidation of copper is governed by the outward lattice diffusion and grain boundary diffusion of copper ions at the interface. The lattice diffusion favors the formation of $\mathrm{Cu}_{2} \mathrm{O}$ phase whereas grain boundary diffusion favors the formation of $\mathrm{CuO}$ phase. In the present work, a fine copper powder is taken as starting material for thermal oxidation to increase the grain boundary diffusion and to study its on phase formation. Further, to suppress the grain boundary diffusion the starting material is chemically passivated with diethylenetriamine and olelamine to chameically passivated the surface defects. Thermal oxidation of these pre-treated materials is carried out in open air at temperature $500{ }^{\circ} \mathrm{C}$ and $700{ }^{\circ} \mathrm{C}$ to study the phase formation. The resulting materials are characterized by $x$-ray diffraction and scanning electron microscopy. These studies clearly confirm that grain boundary diffusion or defect mediated diffusion due to small particle size and more surface atoms of copper favor the formation of $\mathrm{CuO}$ at low temperature in case of pure copper, whereas the chemical passivation and high temperature heating favours the formation of $\mathrm{Cu}_{2} \mathrm{O}$ phase and hence the resulting material is biphasic. Hence, the present study is useful information in controlling the phase formation of copper oxide to obtain more photoactive material that is $\mathrm{CuO}$.
\end{abstract}

Keywords: Thermal Oxidation, copper, lattice diffusion, grain boundary diffusion, $\mathrm{CuO}$ and $\mathrm{CuO}_{2}$ phases.

\section{Introduction}

There has been a growing demand for more energy generation and energy storage due over fast depletion of world's energy resources, over population growth and technological developments with time [1]. It has been well recognized that the solar energy is abundant, clean, sustainable and various possibilities are existing to convert this to the more useful form of energies, one of them is the electricity that can be generated by photovoltaic (solar) cells [2]. There has been continuous search of new materials and refinement of existing semiconductors as photovoltaic active materials to design these cells that can be a low cost, efficient, durable and a long lasting. In this respect, certain semiconductors like I-VI, II-VI, IV-VI compounds, metal oxides, organic materials, and semiconducting polymers have been identified as potential materials for energy conversion applications due to ease of formation and processing [2]. Majority of these are prepared both in their bulk and nanostructure forms to reduce the cost and to increase the efficiency of solar cells.

In the recent years the transition metal oxides have attracted much attention because of their ease of synthesis and size dependent optoelectronic properties [3]. Among these are zinc oxide ( $\mathrm{ZnO})$, titanium oxide $\left(\mathrm{TiO}_{2}\right)$ and cupric oxide $(\mathrm{CuO})$ etc. stand as prominent ones. The $\mathrm{ZnO}$ and $\mathrm{TiO}_{2}$ are wide band gap materials and they lack effective absorption of solar spectrum and they must be combined with certain organic dyes and polymers to make them photovoltaic active in the visible region of spectrum. These structures work mainly under electrochemical environments and hence are classified as photo electrochemical solar cells, or a simply Gratzel cells [4]. The cupric oxide (copper monoxide $(\mathrm{CuO})$ ) is an interesting semiconductor of oxide family. It's optical band gap is $1.2 \mathrm{eV}$ that is most suitable for solar cell applications and it can easily be converted as ptype material [5]. Further its advantage is that it is low cost, abundant, environmentally benign, and easily synthesizable and having direct band gap with high absorption coefficient [6]. In fact, Braver et al. had designed first kind of humidity sensor of $\mathrm{CuO}$ semiconductor way back in 1931. Recently this material has generated renewed interest due to its potential applications in other areas such as optoelectronics [7], flexible supercapcitors [8], catalysis [9], lithium ion batteries [10], gas sensors [11] and good absorbent to remove highly toxic ions from ground water [12]. Copper oxide exists in two stiochometric forms, one is cuprous oxide $\left(\mathrm{Cu}_{2} \mathrm{O}\right)$ and another is cupric oxide (CuO). The former has a more band gap that is $2.137 \mathrm{eV}$ and hence is less suitable for photovoltaic applications, still there are certain reports of using this material to constitute solar cells [13]. A simple thermal oxidation of copper is a straight forward method of obtaining these oxide semiconductors. It has been suggested that outward lattice diffusion and grain boundary diffusion or defect assisted diffusion are two main mechanism for driving copper ions from bulk copper (substrate) to the interface for thermal oxidation process. The former process favors the formation of $\mathrm{Cu}_{2} \mathrm{O}$ phase and latter $\mathrm{CuO}$ phase. In this paper we report 
studies on thermal oxidation of copper under different pre-treated conditions of copper powder to control the second mechanics and its effect on the formation of $\mathrm{CuO}$ and $\mathrm{Cu}_{2} \mathrm{O}$ phases.

\subsection{Materials}

\section{Experimental Details}

All the chemicals used in the present work were of analytical grade, a fine copper metal powder (less than $1 \mu \mathrm{m}$ ) was obtained from (Himedia), Diethylenetriamine (DETA) $\left(\mathrm{C}_{2} \mathrm{H}_{13} \mathrm{~N}_{2}\right)$ and Oleylamine (OA) $\left(\mathrm{C}_{18} \mathrm{H}_{37} \mathrm{~N}\right)$ were obtained from (sd-Fine Chemicals, India).

\subsection{Experiment Methods}

Thermal oxidation of pristine copper powder and chemically treated copper powder with amines has been carried out. Thermal oxidation was carried out in a muffle furnace for period of about $60 \mathrm{~min}$. Copper metal powder $(99.999 \%$ ) purity, was used as the starting material. The copper powder was loaded into the crucible, which was then placed in a conventional muffle furnace for thermal oxidation under open conditions. Here heating was carried out at two different temperatures one at $500{ }^{\circ} \mathrm{C}$ and another is still higher temperature that is $700{ }^{\circ} \mathrm{C}$. After heating, the copper powder gets converted into gray/black material that was collected and stored for further characterization. The morphology of these powders was studied by scanning electron microscopy (SEM) (JSM-5900) operated at $30 \mathrm{kV}$. The crystal structure and phase analysis was done by using powder X-ray diffraction (Rigaku smartlab X-ray diffractometer) using a $\mathrm{CuK}_{\alpha}$ radiation $(\lambda: 1.54178 \AA$ ).

Similarly, amine treated copper powder is also subjected to oxidation. Here the required amount of copper powder was grinded sequentially for six hours with DETA and OA separately to achieve the through mixing and reaction. Again the amine treated coppers were fired at $500{ }^{\circ} \mathrm{C}$ and $700{ }^{\circ} \mathrm{C}$ for $60 \mathrm{~min}$ in open conditions. After annealing the powder were collected and washed thoroughly with copious amount of double distilled water and dried, this material is used for further characterization.

\section{Results and Discussion}

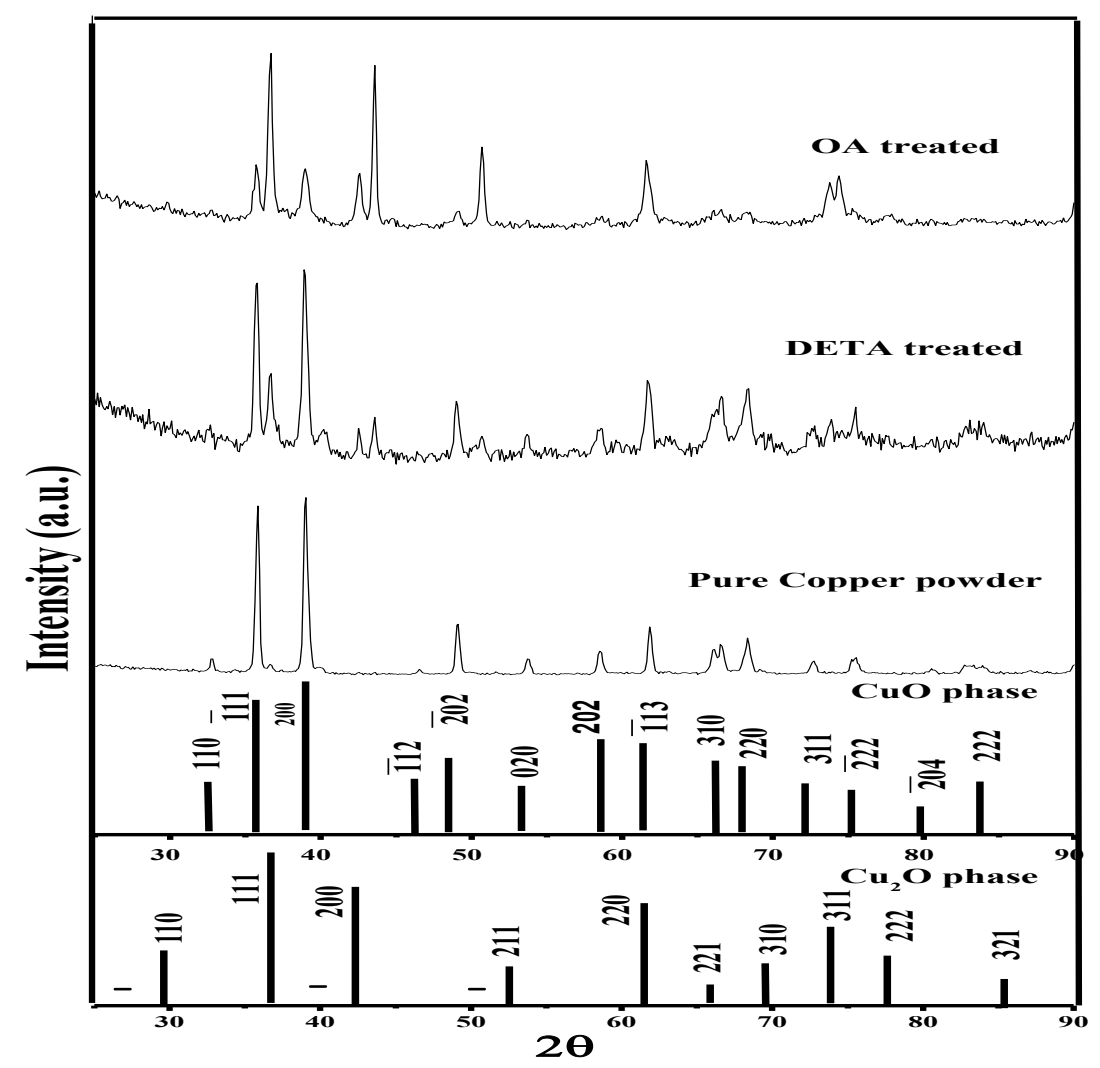

Figure 1: X-ray diffraction patterns of copper oxide of pure, diethylenetriamine (DETA) treated and olelamine $(\mathrm{OA})$ treated copper powders oxidized at $500{ }^{\circ} \mathrm{C}$ for 60 minutes.

X-ray diffraction was employed to study the conversion of copper to copper oxide by thermal annealing. Figure 1 shows the XRD patterns of pure copper, DETA and OA treated copper powders that were 
annealed at $500{ }^{\circ} \mathrm{C}$. The standard reported line patterns of $\mathrm{CuO}$ and $\mathrm{Cu}_{2} \mathrm{O}$ compounds are also shown along with these patterns as vertical lines for the comparison (ICSD no.087126). The standard patterns for $\mathrm{CuO}$ is monoclinic $(a=4.689 \AA, b=3.420 \AA, c=5.130 \AA)$ and $\mathrm{Cu}_{2} \mathrm{O}$ is cubic $(\mathrm{a}=4.27 \AA)$. The observed patterns clearly indicate that annealing of untreated powder shows more sharp peaks as compared to amine treated annealed powder. Hence the amine treatment prior to oxidation of copper suppresses the crystallization process of oxide formation. The particle size in three different cases was estimated using Debye-Scherrer formula $d=\frac{0.9 \lambda}{\beta \cos \theta}$ and they are $72 \mathrm{~nm}, 69$ and $65 \mathrm{~nm}$ for untreated, DETA treated and OA treated oxides, respectively. The pattern of untreated copper oxide matches quite well with $\mathrm{CuO}$ rather with $\mathrm{Cu}_{2} \mathrm{O}$ phase, almost all the peaks of former phase are clearly and distinctly seen. Among these peaks (111), (200), (202) and (113) are the intense peaks of this pattern. The peaks belonging to $\mathrm{Cu}_{2} \mathrm{O}$ are almost absent in case of untreated copper converted to copper oxide. Hence, it can be concluded that oxidation of pure copper powder in open conditions at low temperature $500{ }^{\circ} \mathrm{C}$ leads to formation of pure $\mathrm{CuO}$ phase that is more active photovoltaic material due to its low band gap $(1.2 \mathrm{eV})$ as compared to $\mathrm{Cu}_{2} \mathrm{O}$. However, the patterns of the amine pre-treatment before annealing show a reasonable change in the oxidation process of copper. The two patterns of DETA and OA show the emergence of certain new peaks in addition to the peaks of $\mathrm{CuO}$ phase. Notable changes in DETA annealed pattern are the appearance of new peaks at $2 \theta=36.41^{\circ}, 43.36^{\circ}$ and $61.50^{\circ}$ which belong to the (111), (200) and (220) set of planes of $\mathrm{CuO}_{2}$ phase. These observations are clear indication that DETA treated annealing at $500{ }^{\circ} \mathrm{C}$ favors the formation of $\mathrm{Cu}_{2} \mathrm{O}$ phase against the $\mathrm{CuO}$ phase, hence in this pattern (figure 1) both the phases $\mathrm{CuO}$ and $\mathrm{Cu}_{2} \mathrm{O}$ are coexisting and the material becomes biphasic. Similar observations can be noted in case of OA treated annealing of copper, it shows that (111), (200) and (220) peaks of $\mathrm{Cu}_{2} \mathrm{O}$ are more stronger as compared to DETA annealed and also these peaks are stronger than the prominent peaks of $\mathrm{CuO}$ phase. To study the effect of further increase in annealing temperature on the formation of copper oxide phases, the above exercise was repeated at $700{ }^{\circ} \mathrm{C}$ heating. These patterns along with standard patterns of two different phases of copper oxide are shown in figure 2.

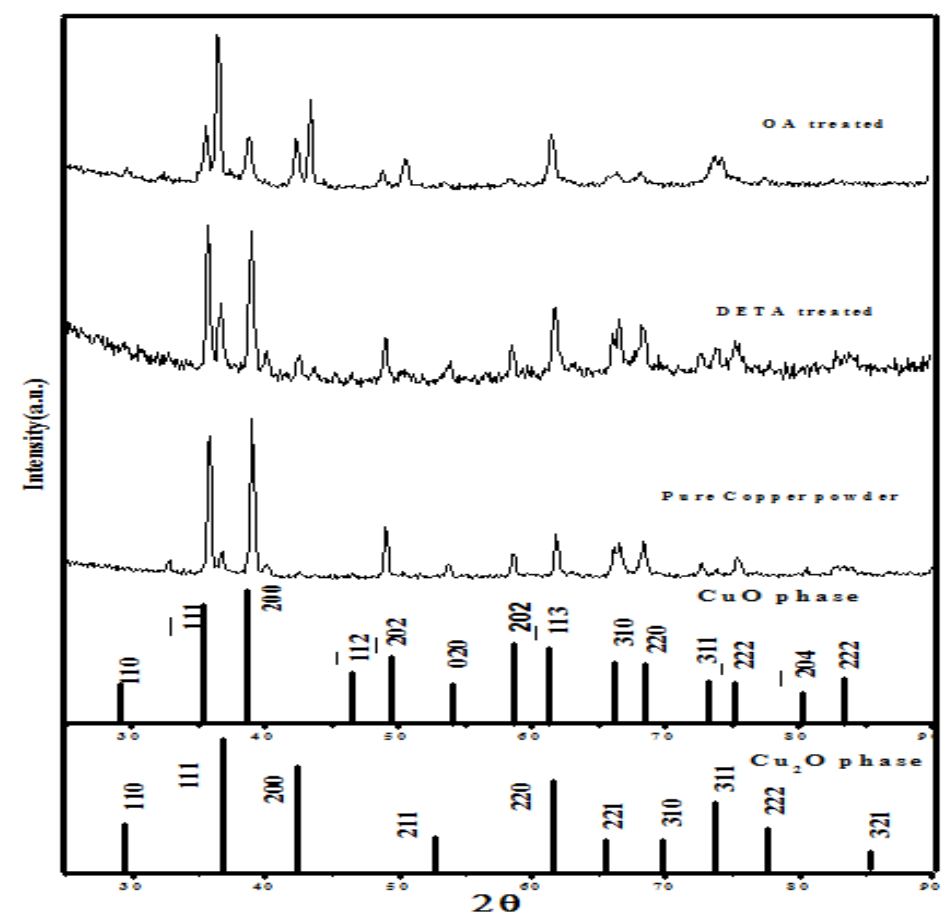

Figure 2: X-ray diffraction patterns of copper oxide of pure, diethylenetriamine (DETA) treated and olelamine (OA) treated copper powders oxidized at $700{ }^{\circ} \mathrm{C}$ for 60 minutes.

It can be noticed that in case of untreated copper the $\mathrm{Cu}_{2} \mathrm{O}$ phase starts emerging and this process becomes more prominent in case of amine treated oxidations. Further, the these patterns were also matched with pure copper powder pattern to see whether there is unreacted material. No such matching is observed. Hence it can be concluded from the X-ray phase analysis that the prior to amine treatment and increase in annealing temperature of pure copper powder favour the growth of $\mathrm{Cu}_{2} \mathrm{O}$ phase against the $\mathrm{CuO}$ phase. 


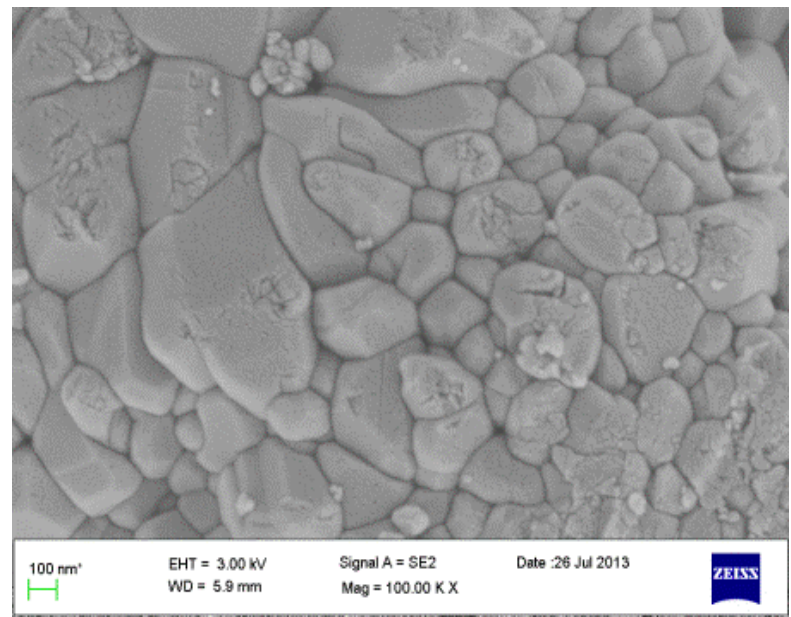

(a)

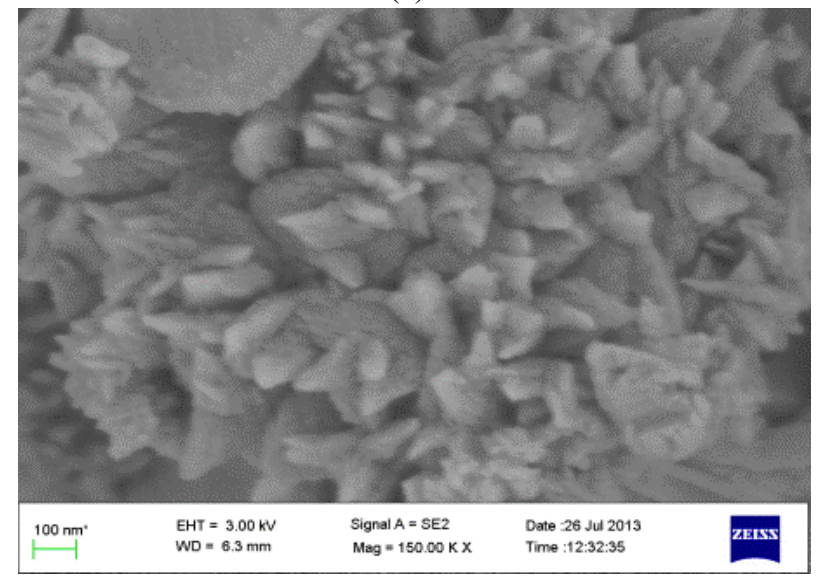

(b)

Figure 3: SEM images of pure copper powder, (a) oxidized at $500{ }^{\circ} \mathrm{C}$ and (b) oxidized at $700{ }^{\circ} \mathrm{C}$ for 60 minutes.

Next, the scanning electron microscopy (SEM) images were recorded on all the samples to study the surface morphology of copper oxide. Figure 3 (a) and (b) show these images for pure copper that was heated at $500{ }^{\circ} \mathrm{C}$ and at $700{ }^{\circ} \mathrm{C}$ temperatures, respectively. in case of $500{ }^{\circ} \mathrm{C}$ heating the structure appears more extended and hence could be better crystalline and of single phasic, whereas the heating at high temperature gives appearance of new phase as whisker. This could be related to the emergence of $\mathrm{Cu}_{2} \mathrm{O}$ phase with increase in temperature. These observations are in accordance with X-ray phase analysis of these samples.

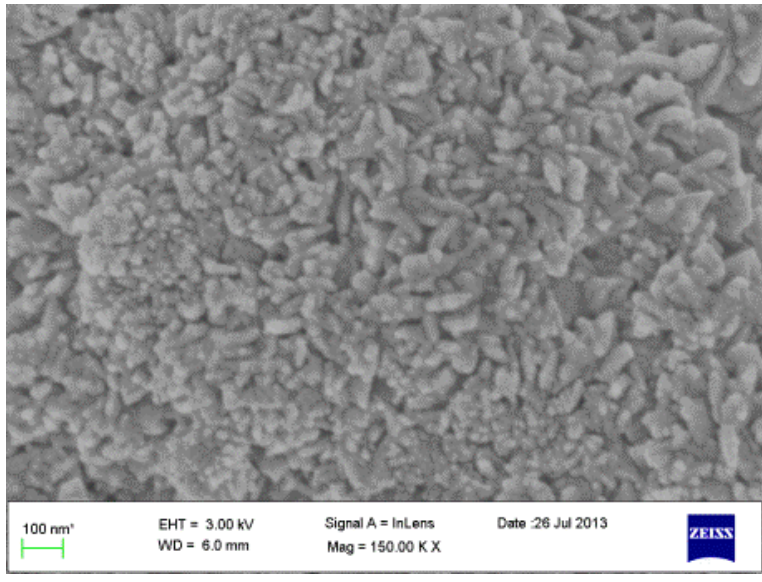

(A)

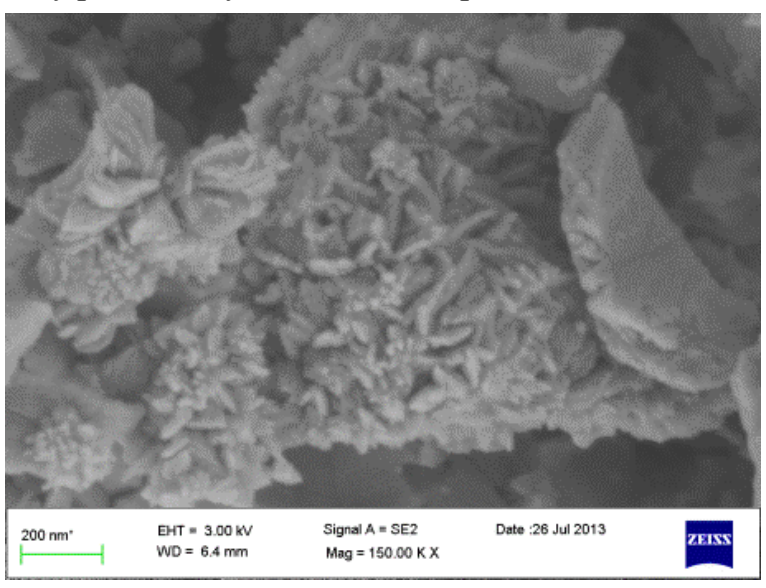

(B)

Figure 4: SEM images of copper powder treated with diethylenetriamine (DETA), (a) oxidized at $500{ }^{\circ} \mathrm{C}$ and (b) oxidized at $700{ }^{\circ} \mathrm{C}$ for 60 minutes. 
Figure 4(a) and (b) show similar SEM images for DETA annealed copper powder to form copper oxide. The extended structure of pure copper annealing breaks into small elongated like structures at $500{ }^{\circ} \mathrm{C}$ heating and it further breaks into smaller size structures at higher oxidation temperature $700{ }^{\circ} \mathrm{C}$. These structures closely resembles to the pure copper annealing at $700{ }^{\circ} \mathrm{C}$. Similar SEM patterns of OA treated oxides at two different annealing temperatures are shown in figures 5(a) and 5(b).

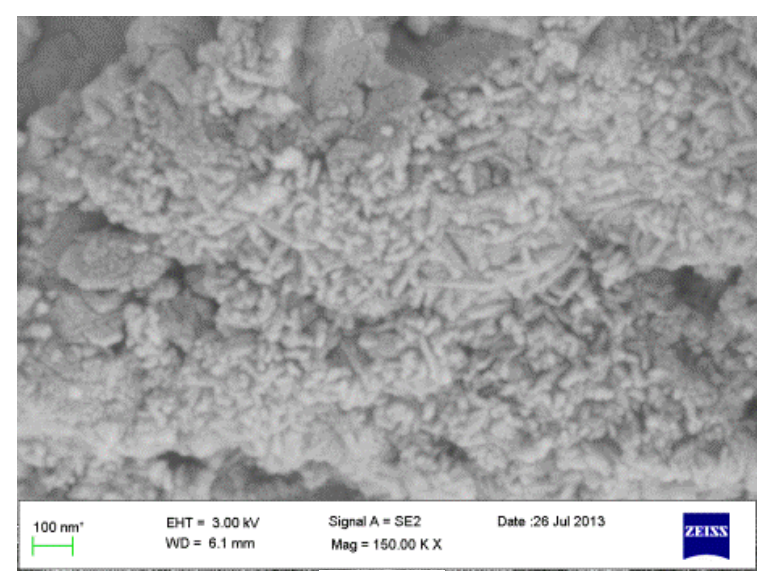

(a)

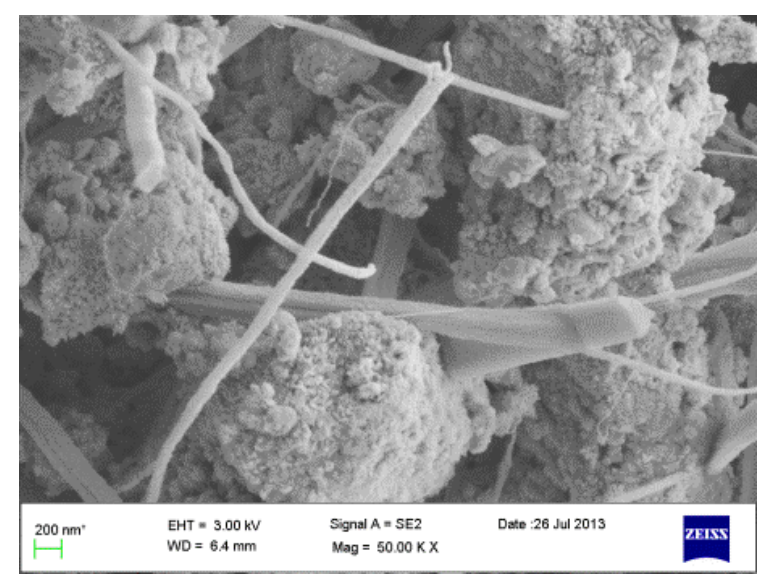

(b)

Figure 5: SEM images of copper powder treated with Olelamine (OA), (a) oxidized at $500{ }^{\circ} \mathrm{C}$ and (b) oxidized at $700{ }^{\circ} \mathrm{C}$ for 60 minutes.

OA treated copper oxides show interesting morphology as compared to DETA treated powders. At 500 ${ }^{\circ} \mathrm{C}$ annealing the structure shows small dense rods, while at higher annealing temperature $700{ }^{\circ} \mathrm{C}$ a fine nanowires with some clusters of $\mathrm{CuO}$ phase appears. These nanowires possesses good apex ratio (length/diameter $>20$ ).

The oxidation of transition metals by heating process is of continued interest and is an interesting process, a lot of work has been carried out in this regards. The surface condition of a metal, the presence of catalysis, temperature of oxidation, oxygen availability, pressure and the time of annealing are some of the important parameters that decide the chemical nature and structure of grown metal oxide. The thermal oxidation of metals is an appealing technique due to fact that the precise control of the above parameters permits to grow bulk to nano-sized metal structures of different phases and such metal oxides find potential applications in verities of electronic devices. Here, the interface between metal surface and open atmosphere is a critical place at which metal ion migrate from the bulk region to combine with the atmospheric oxygen to form the oxide phase. This process can be analysed in terms of Gibb's free energy and by plotting Ellingham diagram (Change in Gibb's energy versus temperature under different pressure) [14]. A general whisker growth, formation of micrometer sized wires, has been well studied process in terms of vapour-solid, vapour-liquid-solid and Frank dislocation growth mechanisms [15]. A typical growth of wire-like structures in case of copper oxide and zinc oxide by thermal process has been analyzed in the literature and four important and independent mechanisms have been proposed [14,15]. These are (i) the absorption of atmospheric oxygen at the metal surface by diffusion process, (ii) nucleation of surface oxide by metal ion and oxygen reaction, this is a diffusion controlled 
process by which metal ions and oxygen gets agglomerated to reduce their surface energy, (iii) nuclear (seeds) arrangement process on the surface of metal to favour the further growth of metal oxide and (iv) morphologically controlled growth of metal oxide, this is mainly controlled by the difference of surface pressure of metal oxide nucleation and metal substrate.

In the recent time, the oxidation of cooper has gained a lot of interest due to fact that a simple oxidation under the controlled conditions of temperature, purity of copper and oxygen partial pressure makes it possible to generate interesting nanostructures, particularly nanowires. This synthetic route is an extremely simple and has potential to generate a highly functional material with low cost of synthesis and that can be easily scalable for a large quantity synthesis. The issue of thermal oxidation of copper is not a well resolved issue. As mentioned above, the copper oxide has two stable phases, one is $\mathrm{Cu}_{2} \mathrm{O}(\mathrm{Cu}(\mathrm{I})$ oxide) and another is $\mathrm{CuO}(\mathrm{Cu}$ (II) oxide), having standard enthalpy of formation $-170 \mathrm{~kJ}^{-\mathrm{mol}^{-1}}$ and $-156 \mathrm{~kJ}^{-\mathrm{mol}^{-1}}$ with melting points $1232{ }^{\circ} \mathrm{C}$ and 1326 ${ }^{\circ} \mathrm{C}$, respectively. Among these, the latter is a more attractive material from photovoltaic application point of view. Hence, there has been a continuous effort to form this material in its purest form. A systematic study of thermal oxidation of copper has been carried out by Zhu et al. in the temperature range from $300{ }^{\circ} \mathrm{C}$ to $900{ }^{\circ} \mathrm{C}$ [16]. Based on this and the others work the thermal oxidation of copper can be divided into two distinct regime of temperatures, one is lower temperature $\left(400^{\circ} \mathrm{C}\right)$ and another is high temperature $\left(800{ }^{\circ} \mathrm{C}\right)$, the former has low activation energy $(40 \mathrm{~kJ} / \mathrm{mol})$ and latter has a high activation energy $(111 \mathrm{~kJ} / \mathrm{mol})$. These processes follow parabolic rate law [17]. In many of the reports it has been claimed that the thermal oxidation of copper begins first with $\mathrm{Cu}_{2} \mathrm{O}$ phase which is then converted to $\mathrm{CuO}$ phase. In both the regimes this phenomenon has been reported. In many cases it is claimed that at the highest possible temperature of oxidation it is $\mathrm{Cu}_{2} \mathrm{O}$ phase that in predominantly dominated in the material. However, Park et al. report that at low temperature $\left(350-450{ }^{\circ} \mathrm{C}\right)$ oxidation of copper in their case directly yields $\mathrm{CuO}$ phase. Regarding the thermal oxidation of copper the following picture arises from these studies. With increase in temperature first there is a formation of $\mathrm{Cu}$ rich $\mathrm{Cu}_{2} \mathrm{O}$ phase at the interface between copper substrate and atmospheric oxygen, due to a large difference in molar volume between copper and its oxide creates high compression stress that leads to high density of grain boundaries of this phase. These parameters with other favorable conditions convert the top layer of $\mathrm{Cu}_{2} \mathrm{O}$ phase into $\mathrm{CuO}$ phase, particularly in the form of nanowires. Here the growth rate is controlled by two independent process of the supply of copper ions to the interface, one is by outward lattice diffusion of copper ions that usually occurs at higher temperature and another is grain boundary diffusion or defect mediated diffusion occurs at low temperature [18]. Recently, Goncalves et al. carried a detailed study on the thermal oxide formation of $\mathrm{CuO}$ nanowires [19]. These authors suggest that the fast supply of copper ions by the short circuit diffusion through grain boundaries favor the formation of $\mathrm{CuO}$ phase.

Most of the work in literature on the thermal oxidation of copper has been carried out on solid plates/discs and hence the formation of $\mathrm{CuO}$ phase above the $\mathrm{Cu}_{2} \mathrm{O}$ phase must govern the lattice and grain boundary diffusion through the latter phase. In the present work we have chosen a fine copper powder as a starting material to facilitate the fast diffusion of copper ions by grain boundaries process and availability of large surface atoms on these particles to form photovoltaic active phase $\mathrm{CuO}$. In order to suppress the grain boundary diffusion and availability of surface atoms for oxidation process, the starting material was chemically passivated with DETA and OA amines. The present results, that is the easy formation of $\mathrm{CuO}$ phase at low temperature oxidation $\left(500{ }^{\circ} \mathrm{C}\right)$ and inhibition of this process in case of amine treatment clearly supports that the grain boundary diffusion or defect mediated diffusion process is primarily responsible for the formation of $\mathrm{CuO}$ phase.

\section{Conclusions}

Open air thermal oxidation of copper has been studied to obtain photovoltaic active cupric oxide semiconductor $(\mathrm{CuO})$. Oxidation of fine copper powder at two different temperatures $500{ }^{\circ} \mathrm{C}$ and $700{ }^{\circ} \mathrm{C}$ has been carried under different pre treated conditions. In order to passivate the surface atoms of these particles to suppress the grain boundary diffusion or defect mediated diffusion, the two different amines such as diethelenetriamine (DETA) and Olelamine (OA) are used. In case of untreated copper powder, there is favorable formation of $\mathrm{CuO}$ phase and it gets converted to $\mathrm{Cu}_{2} \mathrm{O}$ phase at high temperature. On the other hand, the surface passivation of starting material by the above amines reduces the grain boundary diffusion and availability of free surface atoms that leads to the formation of $\mathrm{Cu}_{2} \mathrm{O}$ phase both at low $\left(500{ }^{\circ} \mathrm{C}\right)$ and at high $\left(700{ }^{\circ} \mathrm{C}\right)$ temperatures of oxidation.

\section{Acknowledgements}

Mrs Uma Nerle is thankful to UGC, Government of India for FIP fellowship. The authors would like to thank Department of Physics, Pune University, Pune, and for recording X-ray patterns and Centre for Nano Science and Engineering (CNSE), IISc, Banglore, for SEM facilities. 


\section{References}

[1] A.O.Musa , Akomolafe, M.J.Carter, Production of cuprous oxide, a solar cell material,by thermal oxidation and a study of its physical and electrical properties, Solar energy Materials and Solar Cells, 51,1998, 305-316.

[2] S.E. Habas,H.A.S. Platt, F.A.M.Hest van Maikel, D.S. Ginley, Low-Cost Inorganic Solar Cells: From Ink To Printed Device, Chem. Rev.,110, 2010,6571-6594.

[3] J.Gao,C.L. Perkins, J.M.Luther, M.C.Hanna, H.Y.Chen etal. n-Type Transition Metal Oxide as a Hole Extraction Layer in PbS Quantum Dot Solar Cells, Nano Lett.,11, 2011, 3263-3266.

[4] Michael Grätzel, Photoelectrochemical cells, Nature.,414, 2001, 338-44.

[5] H. Kidowaki, T.Oku and T.Akiyama, Fabrication and characterization of $\mathrm{CuO} / \mathrm{ZnO}$ solar cells, J. Phys.: Conf. Ser.,352, 2012,012022 .

[6] Z. Hai, C. Zhu, J.Huang, H.Liu , and J. Chen, Controllable Synthesis of CuO Nanowires and Cu2O Crystals with Shape Evolution via -Irradiation, Inorg. Chem. , 49,2010, 7217-7219.

[7] S. Manna, K.Das, and S.K. De, Template-Free Synthesis of Mesoporous CuO Dandelion Structures For Optoelectronic Applications, Applied materials and interfaces, 2(5), 2010, 1536-1542.

[8] X. Zhang, W.Shi ,J. Zhu, D.J. Kharistal , W.Zhao, High-Power and High-Energy-Density Flexible Pseudocapacitor Electrodes Made from Porous CuO Nanobelts and Single-Walled Carbon Nanotubes, ACS Nano.,5(3), 2011,2013-2019.

[9] A.P. Jia , S.Y. Jiang, J.Q.Lu , M.F. Luo ,Study of Catalytic Activity at the CuO-CeO2 Interface for CO Oxidation, J. Phys. Chem. C.,114, 2010,21605-21610.

[10] T. Li, X.P. Ai , H.X. Yang, Reversible Electrochemical Conversion Reaction of Li2O/CuO Nanocomposites and Their Application as High-Capacity Cathode Materials for Li-Ion Batterie , J. Phys. Chem. C. , 115,2011,6167-6174.

[11] M. Mashock, K.Yu ,S. Cui ,S. Mao, G.Lu, J.Chen, Modulating Gas Sensing Properties of CuO Nanowires through Creation of Discrete Nanosized p-n Junctions on Their Surfaces, ACS Appl. Mater. Interfaces, 4, 2012,4192-4199.

[12] X.Y.Yu, R.X. Xu , C. Gao, T.Luo, Y.Jia , J.H.Liu , X.J.Huang, Novel 3D Hierarchical Cotton-Candy-Like CuO: SurfactantFree Solvothermal Synthesis and Application in As(III) Removal, ACS Appl. Mater. Interfaces, 4,2012, $1954-1962$.

[13] H.M.Wei,H.B.Gong,L.Chen,M.Zi,B.Q.Cao,Photovoltaic efficiency of $\mathrm{Cu} 2 \mathrm{O}$ solar cells achieved by controlling homojunction orientation and surface microstructure, J.PHYS.CHEM., 116(19),2012,10510-10515.

[14] X.Jiang,T.Herricks,Y.Xia, CuO Nanowires can be synthesized by heating copper substrate in air, Nano Letters., 2(12),2002,13331338.

[15] L. Yuana , W.Yiqian , M. Rediola ,Z. Guangwen, Driving force and growth mechanism for spontaneous oxide nanowire formation during the thermal oxidation of metals, Acta Materialia,59, 2011,2491-2500.

[16] Y.W. Zhu, T.Yu , F.C.Cheong, J.X.Xu , C.T. Lim , V.B.C.Tan, J.T.L.Thong, C. H. Sow , Large-scale synthesis and field emission properties of vertically oriented $\mathrm{CuO}$ nanowire films, Nanotechnology, 16, 2005, 88-92.

[17] Y. Zhu , K.Mimura , J.W.Lim , M.Isshiki, Q.Jiang , Brief Review of Oxidation Kinetics of Copper at $350{ }^{\circ} \mathrm{C}$ to $1050{ }^{\circ} \mathrm{C}$, Metallurgical and Materials Transactions A,37(A), 2006, 1231.

[18] C.Q.Sun, Size dependence of nanostructures: Impact of bond order deficiency, Progress in Solid State Chemistry,35, $2007,1-159$.

[19] A.M.B.Goncalves,L.C. Campos, A.S.Ferlauto, R.G. Lacerda,On the growth and electrical characterization of CuO nanowires by thermal oxidation, Journal of Applied Physics,2009,106. 